\title{
Experimental study of the accuracy of measuring of a central water meter
}

\author{
Ognyan Bekriev ${ }^{1, *}$ and Aleksandar Stanilov ${ }^{1}$ \\ ${ }^{1}$ Technical University of Sofia, Dept. of Hydroaerodynamics and Hydraulic Machines, Kliment \\ Ohridski blvd. №8, Bulgaria
}

\begin{abstract}
The paper presents the results of a study of the error of a central water meter at different modes of water consumption. A stand has been designed for the purpose of the study and tests of the error of the water meter have been performed, in compliance with the requirements of Measuring Instruments (MID) Directive (2014/32/EU). The errors of the water meter have been determined in the area close to its start mode, which is not included in the area of inspection. The measuring errors have been also determined in specific operation modes with frequent starts and stops, associated with the flow of smaller water quantities. The study contains an analysis of the obtained differences in the accuracy of measurement during metrological verification of the water meter and reading on a real site. A quantitative estimate of the established losses in water metering is given.
\end{abstract}

\section{Introduction}

Water meters are measuring instruments designed for continuous measuring of the water quantity passing through them. They are equipped with a measuring device connected to a display. According to their purpose, water meters can be common central meters or control (individual) meters. Common central water meters are used for measuring water consumption in large consumers: residential buildings, public facilities and small companies. A common residential water meter is mounted at the entrance of building plumbing systems, and every consumer has an individual water meter. The type-size and the metrological characteristics of central and individual water meters are different because the central water meter must ensure the water flow at maximum consumption in the building. All water meters are subject to metrological inspection, which can be regular or following repair works. The frequency and the conditions of the inspection depend on the dimension-type and the rated consumption of the water meter. The requirements about the accuracy of measurement applicable for water meters are presented in an ordinance for measuring instruments [1]. The requirements of the Measuring Instruments (MID) Directive (2014/32/EU) [2] in force as of 30 June 2006 have also been included in the ordinance. Figure 1 . shows the period of implementation of the directive for all EU member states.

*Corresponding author: astanilov@tu-sofia.bg 


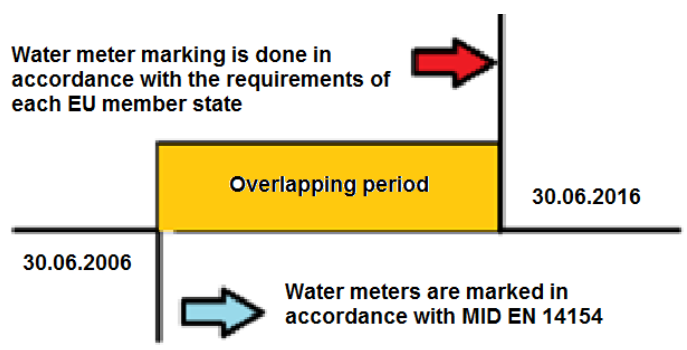

Fig. 1. Period of implementation of the directive MID/EN 14154.

The main metrological properties of water meters are:

Approved type of water meters manufactured before 30 June 2006

Accuracy class of the water meter- A, $\mathrm{B}$ and $\mathrm{C}$

Minimum flowrate - $\mathrm{Q}_{\min }$

Transitional flowrate $-\mathrm{Q}_{\mathrm{t}}$

Rated flowrate $\mathrm{Q}_{\mathrm{n}}$

Maximum flowrate $-\mathrm{Q}_{\max }$
Water meters assessed as compatible and manufactured after 30 June 2016

Measuring range - $\mathrm{R}$

Minimum flowrate - $\mathrm{Q}_{1}$

Transitional flowrate- $\mathrm{Q}_{2}$

Permanent flowrate - $\mathrm{Q}_{3}$

Overload flowrate - $\mathrm{Q}_{4}$

The permissible measuring error of water meters is directly dependant on the measuring range. The latter is limited by the minimum and maximum flowrate the water meter can measure. In addition, the error has different permissible values with regard to any initial, subsequent or post-repair inspection the water meter is subject to. In accordance with [1], the error for every water meter shall be determined at three test points.

\begin{tabular}{c|c|c} 
Point & Approved-type water meters & $\begin{array}{c}\text { Assessed compatibility water } \\
\text { meters }\end{array}$ \\
\hline 1 & $\mathrm{Q}_{\min } \div 1,1 \mathrm{Q}_{\min }$ & $\mathrm{Q}_{1} \div 1,1 \mathrm{Q}_{1}$ \\
2 & $\mathrm{Q}_{\mathrm{t}} \div 1,1 \mathrm{Q}_{\mathrm{t}}$ & $\mathrm{Q}_{2} \div 1,1 \mathrm{Q}_{2}$ \\
3 & $\mathrm{Q}_{\max } \div 0,9 \mathrm{Q}_{\max }$ & $\mathrm{Q}_{3} \div 0,9 \mathrm{Q}_{3}$
\end{tabular}

The areas where the error is determined for approved-type water meters and assessed compatibility water meters are presented in figure 2 and figure 3 . The solid line shows the maximum permissible error for water meters in subsequent inspection and the dotted line shows the permissible error after repair works.

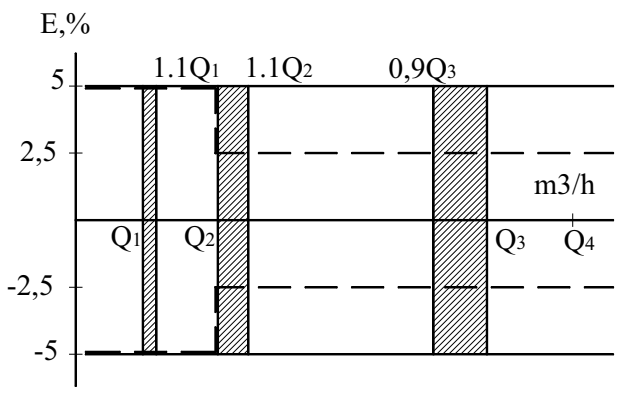

Fig. 2. Areas where the error is determined for approved - type water meters 


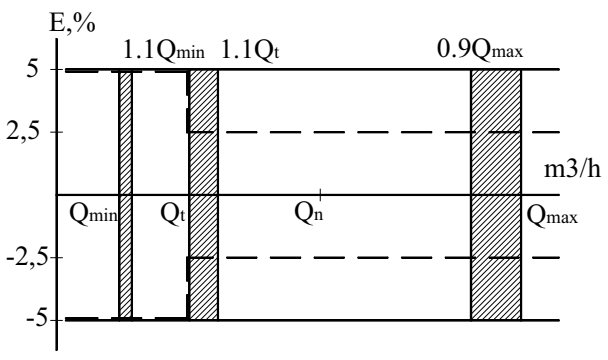

Fig. 3. Areas where the error is determined for assessed compatibility water meters

Figure 2 and figure 3 show that water meters are initially inspected at flowrates ranging around $Q \min$ or $Q_{l}$. For a normal central water meter, these ranges are several times bigger than the minimum ranges of the individual water meters mounted after them. As a result, it is possible to have water flows in the building, which will be measured with a higher error or will not be measured at all. That is why, this paper studies the error of a central building water meter, of assessed compatibility, within the following ranges: start mode $1-(Q s \div Q 1)$, minimum flowrate zone $2-\left(Q_{1} \div 1,1 Q_{1}\right)$ and transitional flowrate zone $3-\left(Q_{2} \div 1,1 Q_{2}\right)$ Figure 4.

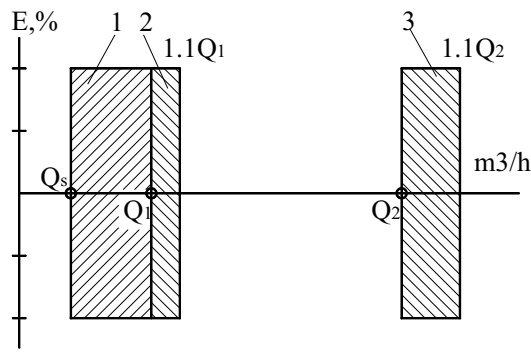

Fig. 4. Test areas

The impact of the time of operation of the water meter for a given operational mode will also be assessed. To minimise the error caused by the smallest scale interval, it is required in laboratory testing to inspect the water meter for such quantity of water, for which that error shall not influence the test result. Furthermore, there is a requirement according to [1] that water meters inspection must provide a movement by at least one turnover of the smallest scale interval. Normally, one turnover of the smallest scale interval corresponds to 11 . In lowest operation modes, the testing time differs from the work time of the water meter in normal operational conditions. Therefore the second task of this paper is to establish if a difference exists in the measuring error depending on the time of operation.

The objectives of this work are:

- To perform a study of the error of a water meter in compliance with the requirements of Measuring Instruments (MID) Directive (2014/32/EU). The study's purpose is to show whether the water meter corresponds with the regulatory requirements.

- To perform tests about the error of the water meter at operation modes with debits close to its start mode $1-\left(Q_{s} \div Q 1\right)$. The reason for setting this objective is that several individual water meters are installed after the common central water meter. The individual 
water meters have smaller dimension-types and their metrological properties allow them to let smaller flowrates. The smaller flowrates of the individual water meters get into the area of the central water meter's start mode.

- To study how the water volumes smaller than 11 flowing through the central water meter impact its metering results.

\section{Experimental study}

Figure 5 presents a diagram of a stand where tests are made on a central multi-jet water meter with the following metrological properties: Permanent flowrate $Q_{3}=16 \mathrm{~m} 3 / \mathrm{h}$, measuring range $R 100$, horizontal mounting $H$, nominal diameter $D N 40$, and start flowrate determined by the manufacturer $Q s=56 \mathrm{l} / \mathrm{h}$. The measuring instruments for measuring the main values are, as follows: a weighing scale 6 of the type B15T with a weighing range from $20 \mathrm{~g}$ to 15 $\mathrm{kg}$ and equipped with a 121 weighing vessel has been used for measuring the quantity of water flowing through the water meter. Chronometer 7 has been used together with the scale to determine the flowrate (test mode). A thermometer 10 and a manometer 9 have been used to measure the water properties during the tests. A pumping unit 6 has been used to supply the stand with water. A valve 3 is responsible for setting the different modes. Valves 4 and 5 are only used to start and stop the water in the system. A straight section of $800 \mathrm{~mm}$ has been provided through the water meter and the section after that is $400 \mathrm{~mm}$. The measuring instruments used in the test have calibration certificates expiring in 2023.

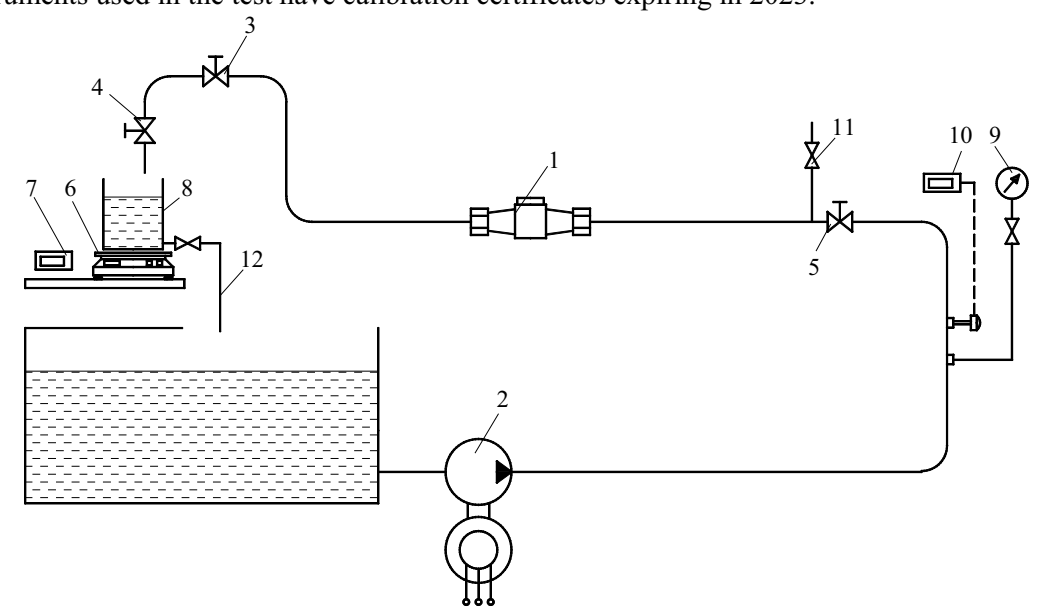

Fig. 5. Diagram of a stand

The tests for determining the error of the water meter have been performed in the following order:

- Launch pumping unit 2 and set the respective mode by using valve 3 and chronometer 7.

- $\quad$ Close valve 4 , reset the weighing scale and the chronometer and write down the indications of the water meter.

- $\quad$ Open valve 4 and starting the chronometer. When the vessel reaches $8 \mathrm{~kg}$, close valve 4 and stop the chronometer.

- $\quad$ Register the indications of the weighing scale, the stopwatch and the water meter display. Three tests are performed for every flowrate. 
The quantity of water used in the tests $-10 \mathrm{~kg}$, has been chosen with regard to the smallest scale interval of the water meter corresponding to $50 \mathrm{ml}$. Therefore the imported metering error will be $0.5 \%$.

The error of the water meter is determined with the following relation:

$$
E=\frac{V_{W}-V_{e}}{V_{e}} .100, \%
$$

Where:

$E$ - Error of the water meter, $\%$

$V_{W}$ - Volume, measured by the water meter, $m^{3}$

$V e-$ Volume, measured by the weighing scale, $m^{3}$

$$
V_{e}=\frac{m}{\rho} k, m^{3}
$$

$m$ - indication of the weighing scale, $\mathrm{kg}$,

$\kappa=1.00106-$ coefficient of correction. The coefficient of correction $\kappa$ is shown in [3], and measures the impact of the difference in the volumes of equal masses - water and reference weights, on the weighing scale indications.

$\rho$ - water density, $\mathrm{kg} / \mathrm{m3}$;

The density of the water is determined by measuring its temperature and using the following relation [3] :

$$
\rho=999,9197-0,000899 T^{0,25} \mathrm{~kg} / \mathrm{m}^{3}
$$

$T$ - temperature of the water, ${ }^{\circ} \mathrm{C}$

The flowrate during the test is determined by using the following relation:

$t$ - testing time, $s$

$$
Q=\frac{V_{e}}{t}, m^{3} / s
$$

The tests for determining the impact of time for the work of the water meter are performed in the following order:

- $\quad$ Launch the pumping unit and set it to the desired work mode. In this case, a work mode closer to the minimum is chosen $Q_{1} \div 1,1 Q_{1}$.

- $\quad$ Perform tests to determine the error in continuous work mode and work modes with interruptions at specific equal quantities $V n$ passing through the water meter for the same quantity of $10 \mathrm{~kg}$. The specific quantities are, as follows: $10 \mathrm{~kg}$ for the continuous test, and $2.5 \mathrm{~kg}$ for the measuring with 4 interruptions. These two tests comply with the requirements given in [1], in specific, there is a full movement of at least one turnover of the smallest scale interval of the water meter.

Tests are also performed to determine the error of the water meter with interruptions at smaller volumes, which do not correspond to a full movement of the smallest scale interval of the water meter. Those modes have been selected for equal volumes of $0.25 \mathrm{~kg}$ with 40 interruptions and $0.5 \mathrm{~kg}$ with 20 interruptions. When stopping and restarting the water meter, the indication arrow must have stopped completely before the next equal quantity is launched.

The tests are performed in the following order: 
- $\quad$ After setting the test mode, the weighing scale should be reset and the starting indications of the water meter must be noted.

- $\quad$ Open valve 4 and monitor the indication of the weighing scale.

- $\quad$ When the weighing scale indicates the quantity pre-selected for the test, valve 4 should be closed and the testing team should wait until the water meter arrow stops moving completely, then open valve 4 and launch the next equal quantity. The tests continue until the total quantity of $10 \mathrm{~kg}$ has passed through the water meter.

- Note the indications of the weighing scale and the final indications of the water meter.

\section{Results}

Determining the error of the water meter.

To determine the error of the water meter based on $Q_{3}$ and $R$ according to [1], two of the main test modes must be set - points 3 and 4 of table 1 . The error of the central water meter between its starting mode $Q_{s}$ and the minimum flowrate $Q_{1}$ is also an object of interest. That is the reason to perform three measurings within that range.

Table 1. Test points.

\begin{tabular}{|c|c|c|}
\hline \multicolumn{3}{|c|}{$\mathrm{Q}_{3}=16 \mathrm{~m} 3 / \mathrm{h}$ DN=40mm R100 } \\
\hline \multicolumn{3}{|c|}{ Setting the test points } \\
\hline 1,2 и 3 & 4 & 5 \\
\hline $\mathrm{Q}_{\mathrm{s}} \div 1,1 \mathrm{Q}_{1}$ & $\mathrm{Q}_{1} \div 1,1 \mathrm{Q}_{1}$ & $\mathrm{Q}_{2} \div 1,1 \mathrm{Q}_{2}$ \\
\hline $56 \mathrm{l} / \mathrm{h}$ & $160 \div 176 \mathrm{l} / \mathrm{h}$ & $256 \div 281,6 \mathrm{l} / \mathrm{h}$ \\
\hline
\end{tabular}

Figure 6 shows the diagram of the errors established during the test of the water meter in the selected modes. The diagram clearly shows that the error may reach $70 \%$ at modes close to the start mode. For a building plumbing system it is possible that the water meter works at an operation mode corresponding to the consumption of a smaller number of consumers.

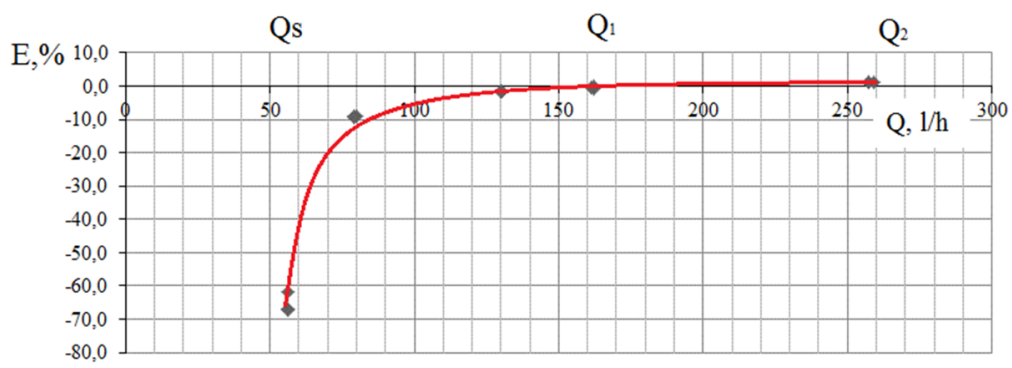

Fig. 6. Diagram of the errors in the selected test points.

Determining the error of the water meter for a different number of start and stop cycles $n$ for a measured volume of water of 101 .

Figure 7 shows the graphic relation of the error of the water meter for a continuous operation mode $Q_{1}=161 \mathrm{l} / \mathrm{h}$ established during the test. For that continuous flowrate, the error of the water meter has been established for the quantity of water of $10 l$ that flowed through it at 1, 2, 20 and 40 cycles. The diagram shows that the error increases when $n$ increases. The 
reason is that the water meter stops with a certain delay, which results in accumulation of the indications.

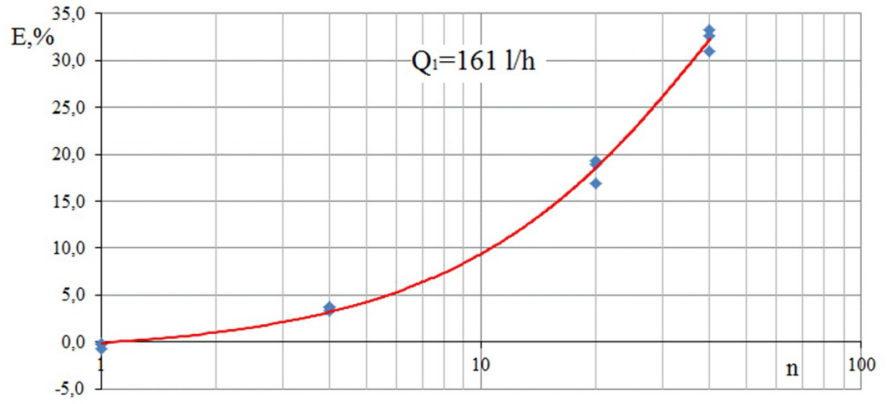

Fig. 7. Graph of errors during cyclic operation.

\section{Conclusion}

On the grounds of the tests performed in the scope of the study, the following conclusions have been reached:

To make sure that the water meter corresponds with the requirements of Measuring Instruments (MID) Directive (2014/32/EU), we tested the water meter with the Weighing method. The metering error in that first test complied with the methodology, and namely $\pm 5 \%$.

In modes close to the water meter's start mode, the measuring error is within the range from $-60 \%$ to $-10 \%$. That means the water meter does not measure the full consumption.

The last test was performed to respond to the requirement that a water meter inspection must be made at a volume corresponding to the smallest scale interval, which usually is 11 . We performed tests with a volume of 101 passing through the water meter at a different number of cycles, and namely 1, 2, 20 and 40 cycles. We obtained a graphic dependence between the number of cycles and the error of the water meter. That test was carried out for a permanent flowrate corresponding to the minimum flowrate - $Q_{l}$. In that test, the measuring errors were within the range from $0,05 \%$ to $30 \%$. The conclusion is that the frequent starts and stops result in higher metering while the metered quantity has not flown through the water meter in the same amount.

\section{References}

1. BS EN 14154-3:2005+A2:2011Water meters. Test methods and equipment

2. Measuring instruments (MID) Directive (2014/32/EU)

3. EN 24185:1993 - Measurement of liquid flow in closed conduits - Weighing method (ISO 4185:1980) 